\title{
Practical Concepts and Productive Reasoning *
}

\author{
Carlotta Pavese \\ Forthcoming in Synthese.
}

March 2021

\begin{abstract}
Can we think of a task in a distinctively practical way? Can there be practical concepts? In recent years, epistemologists, philosophers of mind, as well as philosophers of psychology have appealed to practical concepts in characterizing the content of know-how or in explaining certain features of skilled action. However, reasons for positing practical concepts are rarely discussed in a systematic fashion. This paper advances a novel argument for the psychological reality of practical concepts that relies on evidence for a distinctively productive kind of reasoning.
\end{abstract}

\section{Introduction}

In the same way we can think about tables, trees, and flowers, we can think about tasks, such as swimming, raising one's hand, or picking up the phone. If thinking about something requires deploying concepts for that thing, then we must possess concepts of tasks, just like we possess

*I'd like to thank John Krakauer for many discussions over the years on ideo-motor apraxia and its relevance for my project. I am very grateful to Ian Robertson, Daniel Hutto, Wayne Christensen, Shaun Gallagher, Katsunori Miyahara, as well as the other participants of the Mind in Skilled Performance conference at the University of Wollongong in February 2020 for helpful feedback on the talk on which this paper is based. I am grateful to Sara Aronowitz for discussion and helpful comments on an earlier draft. The comments of two anonymous reviewers were also very helpful. Finally, I am grateful to the Center of Human Abilities for a fellowship that partly supported this research. 
the concepts of tables, trees, and flowers. But what does possessing a concept of a task plausibly amount to?

Although jointly necessary and sufficient conditions for possessing a concept of something and of a task in particular - are hard to come by, it is tempting to presume that one can provide plausible sufficient conditions. Plausibly, if one is to understand the meaning in English of the relevant command - e.g., "pick up the phone!" - one must have a concept of the relevant task - e.g., the task of picking up the phone. Of course, one might possess a concept of picking up the phone without understanding English (for example, if one is not an English speaker). So, understanding the English commands is not necessary for possessing the concept of the command. But it is arguably sufficient: if one is to understand the meaning of the English command 'Pick up the phone', one must possess a concept of picking up the phone.

Call the concept one possesses if one understands the meaning of the corresponding command the 'semantic' concept of that task. Semantic concepts (at least typically) come with knowledge: if one possesses the semantic concept of a task, then one also typically has at least some knowledge about what that task requires one to do - what sort of actions and movements one must undertake to successfully perform it. Some of this knowledge is, at least often, verbally articulable - or declarative. Because of this, a heuristics used by psychologists and linguists to verify whether one possesses the semantic concept for a task is to test whether they possess declarative knowledge of how that task can be performed through verbal tests - i.e., by asking to verbally describe the task or to individuate errors in mistaken descriptions of the task.

Now, suppose one understands the English command "pick up the phone!" well enough, so that one can correctly describe what it takes for one to pick up the phone; and yet, that same person fails to visually recognize phone-pick ups as such and even to be able to visually detect mistakes in somebody else's execution of that task. A subject in this condition might have the semantic concept of the task but would lack what some philosophers might call the observational concept of that task ([Peacocke, 1992], [Campbell, 1996], [Weiskopf, 2015]). Vice versa, possessing the observational concept of picking up the phone does not entail being able to correctly describe that task, just like the observational concepts of square does not require possessing knowledge of the definition of 'square' ([Peacocke, 1992]).

So, when we think of tasks, such as swimming or picking up the phone, there are at least two 
different ways in which we might think of them — via a 'semantic' concept — or observationally — via an 'observational' concept. This paper is about whether, in addition, there are such things as practical concepts - whether, in other words, just like we can think of a task semantically or observationally, we are also able to think of that task in a distinctively practical way, via a practical concept, and about what that would amount to. ${ }^{1}$ My primary aim is to explore a novel argument for positing practical concepts, one that improves on some recent arguments for the existence of concepts with the functional profile of practical concepts in some key respects. In the recent debate, it has been argued that concepts with the functional profile of practical concepts are needed to solve the so-called interface problem. ${ }^{2}$ Call this the interface argument for practical concepts. As we will see, this interface argument for practical concepts comes with several presuppositions -i.e., that there is a genuine interface problem, that there is such a thing as subpersonal motor representations, and that appealing to practical concepts would solve the interface problem, if there was one. By contrast, the argument I will develop for practical concepts depends on none of these presuppositions. Rather, it entirely bears on the psychological reality of a distinctive kind of productive reasoning. As such, the argument provided here attains a generality that the interface argument lacks.

Here is the plan. $\S 2$ overviews the role of practical concepts in current literature in the philosophy of mind and psychology and then discusses the interface argument. $\S 3$ provides a more precise functional characterization of practical concepts, on which practical concepts are dedicated mental representations that enter in a distinctively productive kind of reasoning. $\S 4$ introduces and discusses a widely studied motor deficit as ideo-motor apraxia. $§ 5$ discusses a preliminary argument for the psychological reality of a distinctively productive kind of reasoning arising from the discussion of ideo-motor apraxia and highlights the limit of such an argument. $\S 6$ discusses more evidence from the study of ideo-motor apraxia that rules out certain prominent explanations of the phenomenon and also suggests the psychological reality of productive reasoning. On these bases, $\S 7$ refines the argument. $\S 8$ considers some objections and $\S 9$ compares my discussion to recent discussions of ideo-motor apraxia.

\footnotetext{
${ }^{1}$ This essay remains neutral on whether, in addition to observational, semantic, and practical concepts, there are also phenomenal concepts in [Chalmers, 2004]'s sense.

${ }^{2}$ As raised by [Butterfill and Sinigaglia, 2014].
} 


\section{Practical concepts in the cognitive sciences and the interface argument}

The idea that there are distinctively practical ideas and concepts figures prominently in the current debate about knowledge-how and skills and tends to be associated with intellectualism about know-how. [Stanley and Williamson, 2001] have appealed to 'practical ways of thinking' and have drawn an analogy between practical ways of thinking and first-personal ways of thinking (cf. [Stanley, 2011, pp. 98-110]). ${ }^{3}$ In [Pavese, 2013], [Pavese, 2015b], I talk about 'practical Fregean senses' and in [Pavese, 2015a], [Pavese, 2017a], I talk about 'practical concepts'.

The main reaction to intellectualists' appeals to practical concepts has been outright skepticism -i.e., skepticism that something like practical concepts could be an intelligible, as well as not $a d$ hoc, theoretical posit that could play a substantial role in psychological theories of skillful behavior (e.g., [Noë, 2005], [Schiffer, 2002], [Glick, 2011]). In [Pavese, 2015b], I tried to address this intelligibility challenge and I set out to show that practical concepts can be thought of as kind of Fregean practical senses, which in turn can be modeled as computer programs. This rehabilitation of practical concepts has been only partial, however, because, as focused on the issue of intelligibility as I was, I made no attempt to provide evidence for their psychological reality. Furthermore, in that work, I identified practical concepts with Fregean senses (i.e., abstract objects of sort), and this identification might increase rather than diminish concerns about the psychological reality of practical concepts in those who are independently skeptical of the psychological reality of Fregean senses (cf. [Quine, 1960], [Fodor, 998a], [Mosdell, 2019]).

This widespread skepticism towards practical concepts is not fully justified, however. The idea that there are concepts with the functional profile of practical concepts is not ad hoc nor exclusive to intellectualism. Indeed, it is for at least the last thirty years that philosophers of psychology and of cognitive science have been talking about concepts that, like practical concepts, dissociate from semantic concepts and observational concepts and that are essentially connected to skillful behavior (especially motor behavior).

\footnotetext{
${ }^{3}$ From the little they say about practical ways of thinking, it is hard to say whether either [Stanley and Williamson, 2001] or [Stanley, 2011] thought of practical ways of thinking as concepts or what else (cf. [Pavese, ming] for discussion).
} 
In the context of a general taxonomy of species of thoughts, [Peacocke, 1988, pp. 49-50] talks about 'action-based ways of thinking'. [Peacocke, 1988, pp. 49-50] sketches a broadly Fregean argument for thinking that there ought to be concepts of this sort. He notes that 'a particular type of gesture, which a subject is able to make on demand ... may be thought by the agent in such a (practical) way; when thought of it in such a way, it may come as a surprise to him to see precisely what shape his limb traces when he makes the gesture thought of in that way'. In other words, for gestures just like for stars, Peacocke points out that one can concoct a Fregean puzzle and this is a reason for thinking that there are different ways of individuating gestures - action-based ways of individuating gestures versus observational and semantic ways. ${ }^{4}$

Even more explicit about the importance of practical concepts for know-how is [Israel et al., 1993], who first introduces the notion of 'executable ideas'. [Israel et al., 1993, p. 539] argues that, in order to possess know-how, an agent ought to have ideas of 'various executions'. However, they note that not every idea will do: "For example, Brutus might think of a certain type of movement as 'the type of movement that will be required to kill Caesar when I have the opportunity'. This may be an idea of the very type of movement he needs to execute. But it is not the sort of idea of a movement that can guide the formation of a volition." The relevant idea must be executable.

This thought that there are distinctively practical kinds of concepts has proven especially fruitful for empirically oriented philosophers studying the psychological mechanisms underlying intentional motor behavior. Indeed, several philosophers of cognitive science have followed [Peacocke, 1988] and [Israel et al., 1993] in positing distinctively practical concepts. Following [Israel et al., 1993], [Pacherie, 2000] talks of 'basic action concepts'. According to [Pacherie, 2000, p. 424], basic action concepts are components of particular kinds of intentions - or prior intentions - they are essentially connected to motor representations and actions, which can come apart from other concepts one might have of the same task. Along similar lines, [Pacherie, 2011, p. 7] argues that there are such things as 'executable-action concepts' - concepts that can dissociate from semantic concepts and that can feature as components of particular kind of propositional attitudes (or beliefs-how), which in turn stand to motor representation as perceptual beliefs stand to perceptual experience.

The same idea can be found elsewhere in cognitive neuroscience, linguistics, and philoso-

\footnotetext{
${ }^{4}$ For a more careful discussion of this Fregean argument for practical concepts, see [Pavese, 2021].
} 
phy of psychology. Cognitive neuroscientists [Gallese and Lakoff, 2005] talk of 'motor concepts' that mediate the fixation of content for more abstract concepts corresponding to the same task (cf. [Wermter et al., 2005]) and that enter in an explanation of skillful motor behavior. The idea that motor concepts are psychologically real has been widely discussed by both psychologists and linguists ([Gibbs Jr, 2003], [Gibbs, 2005], [Hampe and Grady, 2005]). In literature on embodied cognition, [Johnson, 2012] discusses 'embodied concepts'. [Mylopoulos and Pacherie, 2017] discusses 'executable-action concepts'. [Weiskopf, 2020] discusses 'anthropic concepts' that involve practical modes of presentation. [Fridland, 2019] discusses 'practical intentions' and seems to think of them along the lines of [Pacherie, 2011]'s executable-action concepts and [Pavese, 2015b]'s practical concepts.

The most systematic argument for concepts with the functional profile of practical concepts is by [Mylopoulos and Pacherie, 2017] — the interface argument mentioned at the outset. [Mylopoulos and Pacher argue that concepts with the functional role of practical concepts ('action-executable concepts', as they call them) are needed to overcome the interface problem ([Butterfill and Sinigaglia, 2014, 131-133]). When performing motor action, we form intentions — for example, in deciding that pulling the lever offers you a better chance of survival than pushing the button, you form an intention to pull the lever, hoping that this will stop the wheel. These intention will result in our motor system to form a motor representation of the motor goals, by virtue of which one might succeed at reaching and grasping for the lever. This matching of the intention and the execution is not accidental. It is not an accident in your situation that you both intend to pull a lever and you end up with motor representations of reaching for, grasping, and pulling that very lever, so that the outcomes specified by your intention match those specified by motor representations. But what explains this non-accidental matching? The interface problem is introduced by [Butterfill and Sinigaglia, 2014] as the problem of how intentions and motor representations nonaccidentally match and interact in producing skillful behavior, despite the difference in format of these two kinds of representations.

Now, [Mylopoulos and Pacherie, 2017] argue that the interface problem is to be overcome by positing 'action executable concepts' — representations mediating between semantic concepts and motor representations and which can doubly dissociate from declarative knowledge. According to this proposal, what explains the non-accidental lining up of intentions and motor representation is 
an intermediate conceptual representation bridges the gap, so to say, between intentions and motor representations in action.

This interface argument for practical concepts comes with several presuppositions, which weaken its appeal. First, it presupposes that there is an interface problem - that both the conceptual system and the motor system operate on bona fide representations, and each on representations with different formats. So, in this sense, it presupposes that the interface between these two systems is 'translational' (cf. [Weiskopf, 2015] for this terminology). ${ }^{5}$ But not every interface is necessarily translational, nor would everybody agree that the cognitive-motor interface in particular should be understood as translational. For example, on an empiricist construal of concepts, the format of perceptual and motor representations and that of intentions do not necessarily differ ([Barsalou et al., 1999], [Prinz, 2004]).

Second, the argument presupposes that there are subpersonal, nonconceptual representations, which differ in their formats from conceptual representations such as intentions. The existence of subpersonal representations is, however, a matter of great controversy in philosophy of mind - a controversy over which I'd prefer not to take a stance here. Presupposing that such subpersonal representations exist weakens the appeal of the interface argument. A prominent tradition in the philosophy of mind contends that representations must require consciousness, or at least conscious access (e.g., [Searle et al., 1983], [Strawson, 2010]). So, the interface argument for positing practical concepts will not convince those who are opposed to positing subpersonal nonconceptual representations ([Merleau-Ponty, 1962], [Hutto, 2005], [Hutto and Myin, 2012]; [Krakauer, 2019], [Krakauer, 2020]) but who might otherwise be persuaded into thinking that there are concepts with the functional role of practical concepts - concepts which dissociate from the semantic and observational concepts and that have a privileged connection with action. ${ }^{6}$

Third, the interface argument is convincing only if practical concepts are really needed to

\footnotetext{
${ }^{5}$ [Butterfill and Sinigaglia, 2014, 128-129] do argue that motor representations and intentions differ in formats by arguing that there is a difference in format between cognitive imagininations and phenomenologically action kind imaginations. But their argument assumes that differences in format follow from differences in characteristic performance profile.

${ }^{6}$ I myself believe that there are good reasons for positing this sort of subpersonal representation (cf. [Pavese, 2017b], [Pavese, 2019]; [Pavese, 2020]) but I do not want my argument for practical concepts to depend on there being subpersonal motor representations.
} 
solve the interface problem. As pointed out by [Christensen, 2020], however, it is independently quite plausible that the interface problem is to be solved by positing metarepresentational rules for translating thoughts and intention into action, rather than by positing action-executable concepts, understood as intermediate representations between thoughts and intentions on one hand and motor representations on the other. ${ }^{7}$

It is my goal in the following to develop an argument for practical concepts that does not rely on these presuppositions: the weaker its assumptions, the stronger the conclusion of the argument and its potential appeal.

\section{The set-up: the functional role of practical concepts}

In order to develop an argument for positing practical concepts, I need to say more about what I take their functional characterization to be, so that we know from the start what kind of evidence might support the hypothesis that practical concepts are psychologically real.

Following a venerable tradition both in philosophy and cognitive science ([Fodor, 998a], [Carey, 2009], [Pinker, 2007]), I will assume without argument that practical concepts are kinds of mental representations. Of course, this is not the only way to think of concepts. Some think of concepts as abstract objects ([Peacocke, 1992], [Zalta, 2001]); others take concepts to be abilities ([Dummett, 1993], [Kenny, 2010]).

By taking concepts to be mental representations rather than abstract objects, I intend to bypass worries about their psychological reality; and by taking concepts to be mental representations rather than abilities, I intend to side with those who think that concepts are things that explain

\footnotetext{
${ }^{7}$ Indeed, arguably, far from solving it, appealing to practical concepts makes the interface problem even less tractable, if the problem is, as it seems plausible, one of translation. For what insures that, as intermediaries between conceptual and motor representations, practical concepts will not raise an interface problem of their own? The issue arises because for them to facilitate the translation between the code (or format) of intentions and the code (or format) of motor representation, practical concepts would need to be written in a hybrid code - a little conceptual, a little motoric - but there are reasons to be skeptical that any such a thing as 'hybrid code' actually makes sense. If, on the other hand, a hybrid code is simply a code different from both the conceptual and the motoric codes - but somehow resemblant of both - it is not at all clear that the interface problem is overcome. Indeed, a regress of translation threatens to arise.
} 
cognitive abilities rather than the abilities themselves. Thinking of concepts as mental representations differ from an understanding of concepts as abstract entities - i.e., as Fregean senses. And thinking of practical concepts as mental representations differ from an understanding of them as practical senses. So in this sense, I am diverging from how I thought of concepts in [Pavese, 2015a] - as kinds of Fregean senses. However, the divergence is not substantial, as one might think of concepts as mental representations that are typed in terms of the Fregean senses that they express ([Laurence and Margolis, 1999]). Similarly, one might think of practical concepts in the sense assumed here as mental representations that are typed in terms of my previous practical senses.

I will not assume that concepts are the same as conceptions. ${ }^{8}$ Whereas a concept of $x$ can be a simple mental representation of $x$, a conception of $x$ is a definition, a theory of, or a body of (tacit or explicit) knowledge about $x$ ([Higginbotham, 1998, p. 149]; [Peacocke, 1988]) — in other words, it is a complex mental representation of $x$. Though cognitive scientists often identify concepts with bodies of information, not every concept can be accompanied by an implicit or explicit conception, ${ }^{9}$ for if so, a regress would threaten to occur ([Peacocke, 1988, p. 52, fn.4]). ${ }^{10}$ In fact, the equation between concepts and conceptions is particularly implausible for basic observational concepts, and probably also for basic practical concepts. ${ }^{11}$ Finally, I take conceptualizations not to be concepts themselves but rather processes that involve the tokening of concepts. ${ }^{12}$

Concepts are mental representations that are compositional and combinatorial — they can compose to form more complex representations in accordance with structural rules. But not every mental representation that is both compositional and combinatorial is a concept. For a mental representation to be conceptual, it ought to enter in high-order cognitive operations, such as categorization and reasoning, and in propositional attitudes, such as judgments, beliefs, and intentions. Many representations are combinatorial and compositional without being conceptual in this stricter sense. For example, motor representations such as motor commands and subpersonal motor schemas are combinatorial representations but they are not conceptual ([Pavese, 2019], [Pavese, 2020]) in that

\footnotetext{
${ }^{8}$ See [Higginbotham, 1998] and [Ezcurdia, 1998].

${ }^{9}$ Cf. [Murphy, 2004], [Machery, 2009] for an overview of the psychological literature on concept.

${ }^{10}$ I did say that semantic concepts often come with (even explicit) knowledge, but this is not to be understood as definitional; rather it is to be understood as a criterion for semantic concepts' possession.

${ }^{11}$ I am not endorsing atomism about concepts either ([Fodor, 998a], [Quilty-Dunn, 2021] for here I allow that some concepts might be complex representations. But I am sympathetic to it.

${ }^{12} \mathrm{I}$ am grateful to a referee for urging me to clarify these issues.
} 
they are not supposed to figure in reasoning. ${ }^{13}$ And perceptual representations might be combinatorial and compositional ([Lande, 2018], [Lande, 2020]) but they do not qualify as conceptual for the same reason.

By reasoning, I mean an inferential transition that is subject to epistemic rules and is, as a result, epistemically assessable (i.e., as good or bad, as rational or irrational, or as justified or unjustified). Reasoning differs from associative transitions in being subject to epistemic rules. It takes thoughts and other propositional attitudes as inputs and outputs — on the model of [Harman, 2008]'s change in view model of reasoning (cf. [Boghossian, 2003]) — and as such, can be sensitive to the knowledge that the subject has. In this sense, I will say that reasoning is a personal-level inferential transition. However, I will not assume that reasoning is to be conscious ([Quilty-Dunn and Mandelbaum, 2018]) or even necessarily verbally articulable.

I will take that concepts of any type can figure in some kind of reasoning. For example, semantic concepts can appear in theoretical and practical reasoning. And observational concepts can appear in causal reasoning as well as in spatial reasoning ([Weiskopf, 2015], [Peacocke, 1992], [Campbell, 1996]). ${ }^{14}$ What kind of reasoning do practical concepts enter into? Philosophers talk of 'practical reasoning' as the sort of reasoning we engage when we decide what to do, among a set of alternative courses of action (cf. [Harman, 1976], [Bratman et al., 1987], [Broome, 2002]). Here, I would like to distinguish practical reasoning from a distinctively productive sort of reasoning - a kind of reasoning not about what to do but rather about how to produce a certain task. Like practical reasoning, productive reasoning involves propositional attitudes of the subject. It differs from practical reasoning also in that it has as an outcome, not an intention, but rather an executable plan — or as I will call it, a productive intention. A productive intention is an 'effective' intention to produce a task in a certain way - effective in that it represents that task in terms of commands that are executable by the subject's motor system. The crucial idea is that the whole point of having practical concepts is to provide us with a representational medium that allows us to think about how to perform a task in the most effective way - i.e., in terms of instructions that the motor system can execute - and to form a productive intention as a result. In this way,

\footnotetext{
${ }^{13}$ Cf. [Butterfill and Sinigaglia, 2014] on evidence for thinking that motor representations do not feature in practical or theoretical reasoning.

${ }^{14}$ Though some spatial reasoning might involve non-conceptual representations ([Peacocke, 1992]), it seems widely assumed that observational concepts would figure in spatial reasoning.
} 
the representational media as well as the outcome of productive reasoning is a representation of the task akin to [Pavese, 2015a]'s (more or less complex) practical concepts. Productive intentions represent the task to be performed practically — i.e., via a practical concepts. Other attitudes can feature practical concepts too — such as judgements and beliefs. ${ }^{15}$

\begin{tabular}{|c|c|c|}
\hline Semantic Concept & Observational Concept & Practical Concept \\
\hline Theoretical/Practical Reasoning & Causal/Spatial Reasoning & Productive Reasoning \\
\hline Theoretical Judgement & Observational Judgment & Practical Judgement \\
\hline
\end{tabular}

Table 1: Variety of Concepts, Reasonings, Judgments

As I mentioned, productive reasoning does not need to be conscious nor necessarily verbally articulable, so standard verbal diagnostics for availability might not apply. That does not mean that there is no way to demarcate personal-level inferences from other sort of transitions. ${ }^{16}$ Personallevel inferences are available to central cognition, rather than only available to discrete subpersonal systems, such as the perceptual system and the motor system. As a diagnostics to ascertain if a certain inference is available to central cognition, I will take two conditions to be jointly sufficient: (i) whether it manipulates representations stored in working memory and (ii) whether it hinges upon some general, though not necessarily declarative, knowledge that the subject has and so it is not encapsulated. ${ }^{17}$

\footnotetext{
${ }^{15}$ In particular, just like one might have a perceptual belief that has an observational concept as its component (cf. [Weiskopf, 2015]), one might have a practical belief — that is, one might believe a practical proposition a proposition that has a practical concept as a component, or make a judgment that has a practical concept as a component - a practical judgment. Indeed, I suspect that [Anscombe, 1963]'s practical knowledge — knowledge of what one is doing while doing it - ought to involve practical concepts of this sort.

${ }^{16}$ The personal-subpersonal level distinction is drawn by different people in different ways. See [Drayson, 2014] for an overview.

${ }^{17}$ About (i): the idea is that working memory is not a discrete subpersonal system and is instead the locus of central cognition (e.g., [Baddeley, 1992], [Baddeley, 1996], [D’Esposito and Postle, 2015]) as well as the locus for highly cognitive capacities such as reasoning, learning and comprehension, as well as propositional attitudes ([Prinz, 2004]). If productive reasoning depends on representations in working memory, that is at least some reason to think that productive reasoning is available to central cognition and so personal-level. About (ii): if the productive reasoning is affected by some general (but not necessarily declarative) knowledge of the subject, that would be evidence that it is not encapsulated, and so, in my sense, not subpersonal. So, in the following I will assume that (i) and (ii) are together
} 


\begin{tabular}{|c|c|}
\hline Practical Reasoning & Productive Reasoning \\
\hline Practical Intention & Productive Intention \\
\hline Intention to act & Executable plan \\
\hline
\end{tabular}

Table 2: Practical versus Productive Reasonings, Practical versus Productive Intentions

The next important point is that, as mentioned at the outset, practical concepts and semantic concepts can doubly dissociate. That means that one might possess a semantic concept for that task - and for example understand a command for performing that task — without possessing the practical concept for it, and hence without knowing how to perform it. Second, one might possess a practical concept, and even know how to perform the relevant task, but not be able to understand the corresponding command or verbally describe the task. The same holds for productive reasoning: one might reason productively about how to perform a certain task to form a productive intention, without necessarily being able to articulate one's productive intention or how one got there. And one might have declarative knowledge about how to produce an executable plan without being able to productively reason about how to perform it. So, productive reasoning and declarative knowledge can dissociate.

Finally, I will not assume that concepts and practical concepts are amodal ([Fodor, 998a], [Machery, 2009]) rather than modal-specific ([Barsalou et al., 1999], [Prinz, 2004]). Nor will I assume that they are bits of language of thought or that they have some other format. Indeed, the argument I will develop for the psychological reality of practical concepts leaves room for them to possibly have different formats (linguistic, imaginistic, pictorial or map-like), for it leaves open that productive reasoning might manipulate representations that are not necessarily discoursive (cf. [Camp, 2009])). Though it might well turn out that under some typing of representations, more than one type of representation might have these characteristics, for the purpose of this essay, there is nothing more to being a practical concept than fulfilling this functional role.

This functional characterization of practical concepts captures the core uses of this notion in the literature overviewed in $\S 2 .{ }^{18}$ And it gives us something to work with for ascertaining evidence sufficient for reasoning to be personal-level in the relevant sense.

${ }^{18}$ Some have talked of practical concepts to refer to conceptual representations of affordances. Here, I don't take this feature to enter into the notion of practical concepts, as I am thinking of it. 
for their psychological reality. In particular, given this functional characterization, if there were evidence that there is such a dedicated kind of productive reasoning - conscious or unconscious but personal in the sense of being available to central cognition (in the senses (i) and (ii) clarified earlier) and dissociatable from semantic concepts and declarative knowledge as well as from observational concepts and observational knowledge - then that would be prima facie evidence for positing practical concepts, in the sense assumed here.

\section{The riddle of ideo-motor apraxia}

With a more precise functional characterization of practical concepts in play, this section introduces a preliminary discussion of the neurological deficit known as apraxia. Apraxia is a rather common clinical disorder that affects complex and skilled movements. It usually results from stroke, traumatic brain injury, or degenerative dementias, including Alzheimer's disease and corticobasal ganglionic degeneration. It is particularly common after dominant left hemisphere stroke and can be observed in both limbs ([Sathian et al., 2011]). It often occurs with weakness or other motor deficits, like spasticity, rendering the diagnosis difficult.

There are a variety of different kinds of apraxia but our focus here is on a particular form of apraxia, known as 'ideo-motor apraxia' — the study of which goes back to the pioneering work by [Liepmann, 1900], [Liepmann, 1906]. Ideo-motor apraxia is often defined negatively as "a disorder of skilled movement not caused by weakness, akinesia, deafferentation, abnormal tone or posture, movement disorders such as tremor or chorea, intellectual deterioration, poor comprehension, or uncooperativeness" ([Geschwind and Damasio, 1985]; [Heilman and L., 1993], [Goldenberg, 2008]). It strikingly differs from purely motor deficits such as paresis and ataxia. ${ }^{19}$ Paretic and ataxic subjects show their corresponding symptoms on any occasion — whether the task is environmentally

\footnotetext{
${ }^{19}$ Paresis occurs when the subject is damaged in their corticospinal system - that is, the cortical motor areas and the corticospinal tract that connects the cerebral cortex to the spinal cord. It reflects a problem in transferring motor commands from the cortex to the spinal cord ([Sathian et al., 2011]). The term 'ataxia' is instead used in a specific sense to refer to impaired spatial and temporal coordination of movements or sometimes more generally as a catch-all term for poor coordination, inaccurate and variable movements, dysmetria, and intention tremor. It results from damage to the cerebellum, its input and output pathways in the brainstem, the spinocerebellar tracts or posterior columns in the spinal cord, or large fibers in peripheral sensory nerves.
} 
triggered (bottom-up) or initiated by the subject independently of an environmental trigger (topdown). Also the nature of the motor task - whether it is a simple prehensile action consisting of grasping objects, or tools, or a complex task related to the use of those objects or tools - does not matter: regardless, performance for paretic and ataxic subjects is impaired. By contrast, what is distinctive about ideo-apractic agents is that they are able to perform the same movement skillfully in some conditions but not in others.

First, ideo-motor apraxia is only observable when dealing with complex motor tasks. By and large, apractic patients show relative integrity when it comes to performing prehensile actions to objects on the basis of their structure (e.g., size, shape, and weight), as compared to complex actions related to the use of those objects and tools. ${ }^{20}$ For example, when attempting to reach out and grasp a cup, an apractic patient will perform nearly normally. Second, it makes a difference if the task is environmentally cued or if the agent is asked to initiate the task in absence of an environmental trigger. The environmental trigger can be different for different kinds of gestures (Table 3, Table 4).

Transitive gestures are tasks involving the manipulations of objects or tools, such as picking up the phone, brushing one's teeth, using a comb, cutting, or hammering. Intransitive gestures are the demonstration of conventional symbolic gestures, such as waving goodbye and saluting, doing a thumbs-up, or signaling stop ([Liepmann, 1906], [Geschwind and Damasio, 1985], [Heilman and L., 1993], [Poeck, 1986]). In the case of intransitive gestures, performances depend on two conditions - whether there is an environmental trigger (trigger condition) or not (no trigger condition). For example, an apractic patient might not be able to perform tasks such as "make the sign of the cross" when asked to do so on demand (no trigger condition) but might perform the sign with no problem when entering a church (trigger condition). Even when the task is performed, often their performance on demand reflects improper orientation of their limbs and impaired spatio-temporal organization. In the case of transitive gestures, we can distinguish between three conditions - whether performance involves the tool itself (tool condition) or is only pantomined (no tool/no environmental trigger condition); and in the first case, whether there is an environmental trigger (tool/trigger condition) or whether the task is initiated by the agent in

\footnotetext{
${ }^{20}$ In fact, some describe apractic agents as performing movement errors with their non-paretic hands. Cf. [Goldenberg, 1996].
} 


\begin{tabular}{|c|c|}
\hline Condition & Transitive Gesture \\
\hline No tool/Pantomine & $\boldsymbol{x}$ \\
\hline Tool/No trigger & $\boldsymbol{X}$ \\
\hline Tool/Trigger & $\boldsymbol{\checkmark}$ \\
\hline
\end{tabular}

Table 3: Conditions for transitive gestures

\begin{tabular}{|c|c|}
\hline Condition & Intransitive Gesture \\
\hline No Trigger & $\boldsymbol{X}$ \\
\hline Trigger & $\checkmark$ \\
\hline
\end{tabular}

Table 4: Conditions for intransitive gestures

absence of the trigger (tool/on demand). For example, while an apractic agent may not be able to pick up the phone when asked to do so (tool condition/on demand), the same agent might be able to perform the action automatically when the phone rings (tool/trigger condition).

Often the mistakes involve sequencing errors - for example, when asked to prepare a letter for mailing, an apractic agent might seal the envelope before inserting the note. The importance of environmental triggers for correct performance is shown by the difficulties that apractic agents exhibit in pantomiming tasks (no tool/no trigger condition), where apractic agents are asked to imagine, act out, or pantomine the corresponding movement on demand. Problems with performance in this case are particularly severe ([Liepmann, 1906], [Geschwind and Damasio, 1985], [Heilman and L., 1993], [Poeck, 1986]). For example, an apractic patient might not be able to perform tasks such as "make the sign of the cross" but might perform the sign with no problem when entering a church. When asked to demonstrate how to use a spoon to eat a bowl of soup, apractic subjects might instead pantomime the action of brushing their teeth. Even when the task is performed, often their pantomime reflects improper orientation of their limbs and impaired spatiotemporal organization. For example, an apractic patient might pantomime a tooth brushing gesture with oscillations of greatly exaggerated amplitude, use the forefinger as though it were the toothbrush rather than pantomiming how the handle of the brush should be held, and/or orient the arm and hand inappropriately relative to the head ([Buxbaum et al., 2003]) (Table 5). 
This discussion puts us in position to introduce the so-called 'riddle' of apraxia. The riddle consists in the fact that the disorder of skilled movement manifests differently depending on the condition of the testing ([De Renzi et al., 1980], [De Renzi, 1989]). How is the riddle to be solved?

The fact that performance is impaired only in some conditions and preserved in others motivates thinking that, in contrast with paresis and ataxia, ideomotor apraxia is not simply a motor problem. On the other hand, researchers studying ideo-motor apraxia have long come to the realization that the problem does not seem to be semantic either. In fact, although apraxia has been for long confused with aphasia ([Kertesz and Hooper, 1982]), aphasia and apraxia have been demonstrated to be different deficits. For one thing, aphasics are typically pretty good at motor tasks, regardless of their complexity, as evidenced by studies on gestures [Sekinea and Rosec, 2013]. Moreover, [Lehmkuhl et al., 1983] have shown that the severity of apraxia cannot be understood in terms of defective language comprehension, for patients with the lowest performance in sentence comprehension tests were not equally distributed among the three degrees of severity of apraxia. Moreover, apractic patients can do well on language comphrension tests (cf. [Rapcsak et al., 1995, p. 220]), showing no comprehension problems, as well as generally intact language competence. And even severely apractic agents are typically able to verbally describe the command given to them and what the relevant task requires them to do, showing a good level of memory recollection (cf. [Rapcsak et al., 1995, p.229]). There is no evidence that they are impaired in their ability to acquire new information and new semantic concepts by acquiring novel vocabulary. Indeed, apractic patients typically performs at low-normal levels on tests of both working memory and executive function ([Krakauer and Shadmehr, 2007]). It is also generally ruled out that the deficit can be explained in terms of intellectual deterioration and/or to dementia ([Goldenberg et al., 1986]). Apractic patients perform well on comprehension tests aimed at testing their ability to understand the commands given to them under no trigger conditions. So, although apractic agents typically make errors when they are asked to perform or pantomime a task, the problem cannot be reduced simply to a semantic problem: it is not simply the case that apractic agents do not understand the command given to them. Moreover, apractic agents do well on tests aimed at checking for declarative knowledge and concept possession. For example, BO is able to correctly recognize and name familiar objects and also identify their common uses and functions ([Krakauer and Shadmehr, 2007]). This suggests that the deficit is not due to defective semantic understanding of what subjects are asked to 


\begin{tabular}{|c|c|}
\hline Function & Evidence of possession \\
\hline Semantic concept/knowledge & $\checkmark$ \\
\hline Observational concept/knowledge & $\checkmark$ \\
\hline Motor program/representation & $\checkmark$ \\
\hline
\end{tabular}

Table 5: Ideo-motor apraxia and representations

do and so it is not due to the patients' lack of the relevant semantic concepts. Finally, the problem cannot be identified with the lack of observational concepts either. For patients affected by ideomotor apraxia might perform well when it comes to correctly identifying the correct hand postures in observational tasks ([Hayakawa et al., 2015]) or arranging the photographs in the correct order to illustrate the steps required for performing the action ([Rapcsak et al., 1995]).

\section{An initial argument and a popular explanation}

How can the riddle of apraxia be solved? The crucial difference between the two main conditions of the testing is whether the task is environmentally triggered or not. When it is, apractic patients are able to perform the task correctly. That suggests that in this condition, the patients can form correct motor representations of the tasks and correctly translate those into actions. So, what explains the fact that, in absence of environmental cues, apractic subjects' motor performances are impaired?

One initial thought is that, when the task is environmentally triggered, it is less important for the subject to be able to plan how the action is to be performed. Using the terminology introduced in $\S 2$, we can say that (sufficiently) environmentally triggered tasks do not require the subject to reason productively about how to produce the task and to form a productive intention through such productive reasoning. By contrast, when the task is to be performed in absence of environmental cues, it seems plausible that one would have to plan how to perform it and in this way one would have to form a productive intention. This suggests a prima facie argument from ideo-motor apraxia to psychological reality of productive reasoning: what makes the difference in performance in different conditions of the test is whether (or the extent to which) productive reasoning is needed 
to perform the motor task.

While this sort of story is compatible with the evidence, more argument is needed to make the case that it is the best explanation. A rival explanation consists in thinking of the deficit in terms of the inability to retrieve the relevant motor program/action schema/control policy. ${ }^{21}$ The idea behind this explanation is that tasks that have been encountered before are associated with the corresponding motor programs (or action schema, or control policy) stored in long-term memory. Normal subjects have somehow the ability to retrieve those on demand - pushing a button, so to say. By contrast, apractic subjects lack this ability. On the other hand, environmental cues can compensate and help trigger the relevant motor programs even in absence of this ability. This would explain the riddle of ideo-motor apraxia.

Indeed, this is a rather popular explanation of the deficit. For example, [Macauley and Handley, 2005, pp. 30-31] describe ideo-motor apraxia as a defect in 'motor programming' or in 'selecting the right motor program'. [Jeannerod, 2006, p. 12] describes the phenomenon as the consequence of a 'disruption of the normal mechanisms for action representations'; [Krakauer and Shadmehr, 2007, p. 391] reports it as a popular view of ideo-motor apraxia that 'patients are impaired in their ability to recall stored motor programs'. [De Renzi, 2012, p. 101] says that ideo-motor apractic subjects are affected by a deficit that 'relates to the second level of action organization: they seem to have lost the motor programs associated with various kinds of objects'. According to this popular explanation, different motor tasks, such as as waving goodbye on demand, combing one's hair, brushing one's teeth, or hammering, correspond to different stored motor programs (or action schemas, or motor routines, or control policies). They can be triggered by environmental cues; in absence of environmental cues, these motor programs need to be activated by the subject. On the popular explanation, apractic patients would lack this ability to do this properly.

Now, if the popular explanation were correct, then ideo-motor apraxia would not necessarily have to be a deficit in reasoning at all, let alone in productive reasoning. To see this, compare retrieving a control policy from long-term memory to the task of pushing the right button in a video-game in response to a visual stimulus on the right side of the screen. Suppose I am unable to do that. This inability does not need to be due to an inability to reason in some way or the other

\footnotetext{
${ }^{21}$ This hypothesis is formulated differently from different researchers. Some talk of motor programs, action schemas, while others talk of control policies.
} 
about how to respond to the visual stimulus. It might just require the brute ability to press the right button in reaction to the visual stimuli. Selecting the relevant motor program among several might just be akin to selecting the right button in the video-game — it might just be a matter of a brute ability rather than a reasoning ability or a conceptual deficiency. On this 'video-game model' of ideo-motor apraxia, as we might call it, apractic patients' deficit would not necessarily have to do with their ability to productively reason. ${ }^{22}$

So, this initial argument from ideo-motor apraxia to the psychological reality of productive reasoning ought to be considerably refined and improved. In the next sections, I explain why the popular explanation — and the video-game model of ideo-motor apraxia — is not satisfactory (§6) and so why it is better to think of ideo-motor apraxia as a deficit in productive reasoning $(\S 7)$.

\section{Evidence against the popular explanation}

\subsection{Meaningless gestures}

There are two kinds of findings concerning apractic agents that the popular explanation cannot account for. The first finding is that apractic agents are impaired in their ability to imitate meaningless gestures as much as they are in their ability to perform symbolic gestures on demand. While symbolic gestures are gestures with a meaning — like waving goodbye, saluting, sending kisses meaningless gestures are instead novel configurations of movements with no conventional meaning and which subjects are unlikely to perform habitually (cf. the left outermost column in Fig. 1).

Many different studies have found an impaired ability of ideo-apractic patients in imitating meaningless gestures ([Goldenberg, 1995], [Goldenberg, 1996], [Goldenberg and Hagmann, 1997], [Goldenberg, 1999], [Goldenberg, 2001], [Krakauer and Shadmehr, 2007]; [Osiurak, 2009]; [Goldenberg, 2013]), through what I call the 'Meaningless Gestures Test'. Here, I focus on one study by [Goldenberg and Hagmann, 19

\footnotetext{
${ }^{22}$ Indeed, on the basis of the evidence marshaled so far, one of the first philosophers to discuss ideo-motor apraxia — [Merleau-Ponty, 1962, pp. 523-525, fn 99] — observes "We will not render apraxia comprehensible ..., unless the movement to be accomplished can be anticipated but without being so through a representation." Indeed, [Merleau-Ponty, 1962, p. 142] argues that apractic subjects lack a body schema, which he does not seem to conceive of representationally.
} 

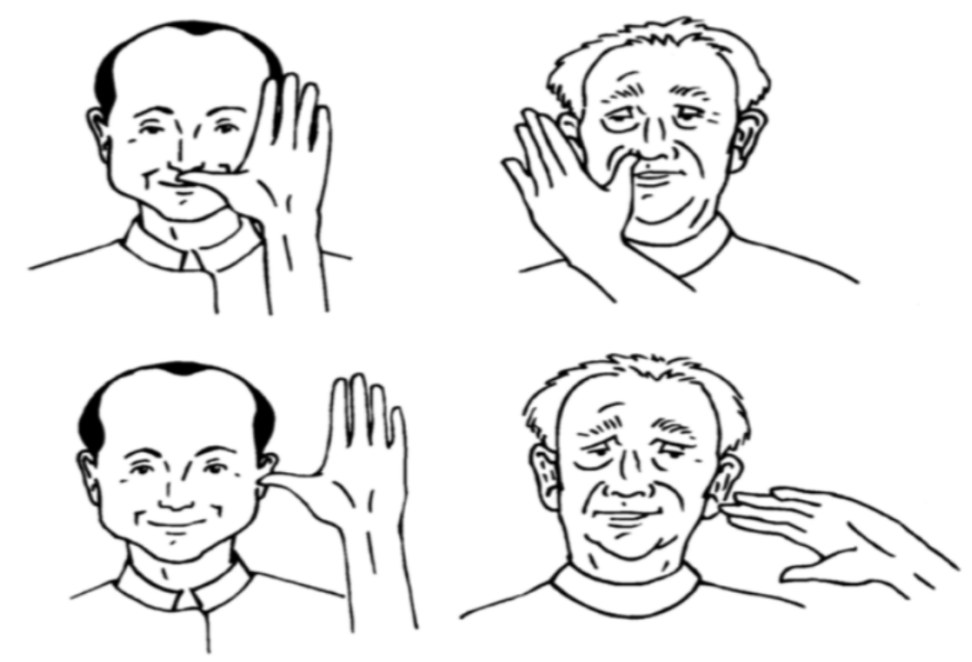

Figure 1: Meaningless Gestures, from [Goldenberg and Hagmann, 1997, pp. 337]

pp. 335-338], involving apractic patients with normal language production abilities and good comprehension of single words and sentences, who perform well on memory and other cognitive tests, such as naming of touched fingers and recognition of right and left. For these subjects, imitation of hand gestures was tested using meaningless gestures involving complex hand positions. This task requires the patients to copy different positions of the hand relative to the head while the configuration of the fingers remained invariant. The examiner sits opposite to the patient and demonstrates the gesture 'like a mirror' with his right hand (cf. left column in Fig. 1). The patients start imitation immediately after the demonstration. Scoring considers only the final position of the hand and did not take into account hesitation/searching movements or self-corrections during the course of the movement nor does it consider minor variation of the angle of the hand or of the degree of extension of single fingers. While healthy subjects and subjects with right-hemisphere damage can perform these imitations virtually flawlessly, apractic patients make all sort of mistakes (cf. right column in Fig. 1). The contrast between imitation of meaningless gestures and evocation of familiar gestures from long-term memory is particularly impressive when the shapes of the intended gestures is similar. For example, both patients correctly touched the temple with the middle finger of the horizontally extended hand when demonstrating a military salute but searched in vain for the correct position of the hand when imitating a gesture which consisted of placing the thumb of the vertically extended hand to the ear. 
These results cannot be explained in terms of a purely perceptual deficit - such as defective perception of the shape of the gestures — for the same subjects could imitate meaningful gestures (cf. also [Goldenberg and Hagmann, 1997], [Peigneux et al., 2000], [Bartolo et al., 2001]) and correct imitation of meaningful gestures engage the same perceptual abilities ([Goldenberg, 2013, p. 91]). Moreover, these findings cannot be explained in terms of a deficit in a simulation mechanism involved in imitation, of the sort posited by 'mirror neurons' ([Rizzolatti et al., 2002], [Rizzolatti and Sinigaglia, 2008]). For mirror neurons only react to meaningful and familiar actions ([Ferrari et al., 2005]). Nor could they be explained in terms of a merely performative/executional level. After all, imitation of gestures was defective even when tested on a manikin rather than on the patients's own body ([Goldenberg, 1995]). In the manipulation of the manikins, subjects were asked to replicate the gestures demonstrated by the examiner with one hand of the manikin. Because the demands of motor execution are fundamentally different between manipulation of a manikin and imitation on oneself, if the problem were executional, it would not necessarily affect the task when performed on a manikin.

In the case of meaningless gestures, it is implausible that the relevant gestures have an associated motor program/action schema/control policy available for retrieval, since these tasks are 'meaningless' - the subjects do not attach any meaning to them that they can retrieve on demand; moreover, these configurations of gestures are novel and have never been performed before ([Goldenberg and Strauss, 2002]). Hence, as several cognitive scientists have observed (e.g., [Krakauer and Shadmehr, 2007, p. 391], [Goldenberg and Hagmann, 1997, p. 338], [Osiurak, 2009, p. 780]), the popular explanation cannot easily explain the Meaningless Gestures Test.

\subsection{The Novel Tool Test}

The second relevant evidence against the popular explanation comes from the Novel Tool Test

— a kind of test widely experimented on apractic patients ([Goldenberg and Hagmann, 1998], [Hodges et al., 2000], [Spatt et al., 2002], [Hartmann et al., 2005], [Goldenberg et al., 2007], [Goldenberg and Sp [Jarry et al., 2013]), in which apractic patients are tested in their ability to find innovating solutions to problem-solving tasks.

In one particular experiment run by [Goldenberg and Hagmann, 1998] (illustrated by Fig. 2), a 
set of six cylinders and six tools were constructed, and one cylinder at a time was put into a socket. A collection of three tools was placed beside the socket and the patient was asked to select the one tool that was best suited for taking up the cylinder, to attach it to the cylinder, and to lift the cylinder out of the socket. This was demonstrated with the last cylinder of the test and with distractor tools different from those used in the test of the same item. The task was demonstrated both verbally and visually, so that the results were not predicated on verbal comprehension. Subjects with ideomotor apraxia were significantly worse in this task, especially in the selection of the relevant tool. The errors of apractic patients mostly concerned the principle of the tool-object interaction - for example, they would press the outer side of a hook against a ring instead of inserting its tip into the opening of the ring. This experiment involving innovating problem-solving tasks was accompanied by tests concerning pantomime of tool use, as well as use of familiar tools on demand. Indeed, only patients with ideo-motor apraxia were found impaired on all three tasks: pantomime of tool use, use of familiar tools, and selection of the novel tools ([Goldenberg and Hagmann, 1998, p. 585]).

In another set of experiments ([Heilman et al., 1997]), subjects were presented with an array of tools for a task but without the most typical tool associated with that task and were then asked to choose the best tool to complete the task among those available. For example, patients were given a partially driven nail but no hammer with a selection of pliers and a needle available. Selection of a tool that could not accomplish the action goal would be scored as an error. For example, if the subject chose a needle to pound in the partially driven nail, it would be considered an error. Patients with ideo-motor apraxia scored significantly worse on this task than patients with brain damage but no apraxia and agents with no brain damage - they would choose a needle over the pliers more often than not - showing a deficit of mechanical problem-solving abilities. In another set of experiments ([Osiurak, 2009]), subjects were asked to use a fork to eat yogurt. Normal subjects would use the bottom of the fork as a spoon. Apractic patients instead would either try to use the top of the fork (unsuccessfully) or they would try to use the bottom of the fork but would fail to use it as a spoon. Instead, they would dig it right into the yogurt. ${ }^{23}$

As [Goldenberg, 2013, p. 135] and others have noted, the popular explanation cannot account for these findings. The inability to retrieve the associated motor program cannot explain this

\footnotetext{
${ }^{23}$ For yet other experiments on the Novel Tool Test, see [Osiurak et al., 2013], [Jarry et al., 2013].
} 


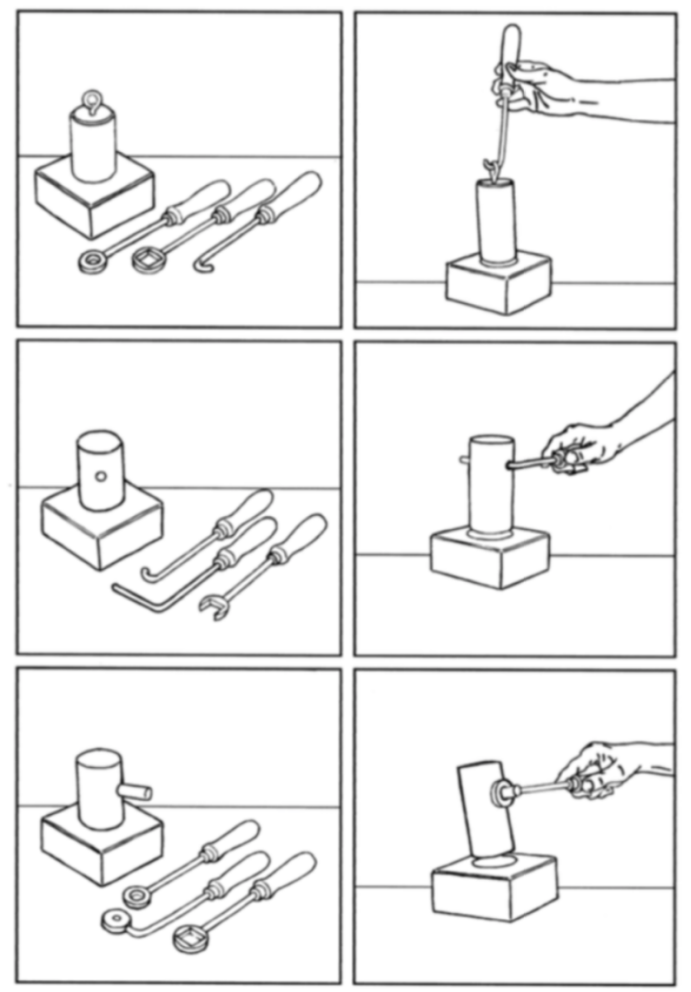

Figure 2: An Example of the Novel Tool Test, from [Goldenberg and Hagmann, 1998, p. 589] 
inability to find innovating problem-solving solutions, for when the task is unfamiliar, it is implausible that the subjects have an associated motor program (or control policy) already available to be retrieved from long-term memory.

\section{A refined argument for the psychological reality of produc- tive reasoning}

In conclusion, the popular explanation cannot easily explain the findings in the Novel Tool Test and the Meaningless Gesture Test: thus, the video-game model of ideo-motor apraxia is not correct. This section explores an alternative explanation of these findings, which sets the stage for a refined argument for the psychological reality of productive reasoning.

The explanation has three steps. The first step is that the Novel Tool Test provides evidence for the importance of a particular kind of mechanical reasoning, for which apractic patients seem to have an impaired capacity $(\S 6.1)$. The second step is that the incapacity for mechanical reasoning and related cognitive processes such as body part coding can also explain other symptoms associated with ideo-motor apraxia, providing a more compelling and unified explanation of the deficit than the popular explanation (§6.2). The final step is that mechanical reasoning satisfies the conditions for being (or being required for) a distinctively productive kind of reasoning ( $\S 6.3)$.

\subsection{Evidence for mechanical reasoning}

Many cognitive scientists explain the results in the Novel Tool Test as a deficiency in a distinctively mechanical kind of reasoning. [Goldenberg and Hagmann, 1998] call it 'mechanical problemsolving' (cf. [Goldenberg, 2013], [Hegarty, 2004] call it 'mechanical reasoning', [Osiurak, 2009] calls it 'technical reasoning'. (cf. also [Jarry et al., 2013], [Osiurak, 2011]), [Osiurak and Badets, 2016]).

How would mechanical reasoning help solve the Novel Tool Test? The general idea is that mechanical reasoning decomposes representations of tools into their functionally significant parts and properties. Since both familiar and unfamiliar objects are composed of the same set of functionally significant parts and properties, and prototypical applications of tools and objects obey the same physical regularities, mechanical reasoning helps us figure out how to use novel tools and objects 
and how to detect alternative ways of using familiar tools and objects.

For example, one might reason from certain properties and parts of a screwdriver how to screw without a screwdriver as follows. Screws are mentally segmented into slits on their head, which provide a plane opposite to the direction of the intended rotation and thus enable the transfer of rotation from the screwdriver to the screw. The functional part of the screwdriver is represented as the blade and its functionally decisive property is represented as its rigidity. The representations of these properties are combined so that the shape and thickness of the blade must match the width and the form of the slit, and its rigidity must suffice for rotating the screw against the resistance of the material into which it penetrates. Through this sort of mechanical reasoning, one might come to the conclusion that any object providing a blade with the same properties might replace the screwdriver, so that, for example, one might equally well screw with a coin or a knife.

While mechanical reasoning might sometimes be involved in more familiar tasks, mechanical reasoning is necessary when the solution is less predefined - for example when participants also have to select one out of several presented tools to complete the action or to determine what steps are needed to achieve the goal, as in the Novel Tool Test (cf. [Osiurak, 2009, p. 2331]). In those cases, analysis of mechanical relationships between possible technical means and possible technical ends is needed to plan the action.

\subsection{Generalizing the explanation}

Impaired mechanical reasoning might explain apractic patients' inability to successfully pass the Novel Tool Test. Can a deficiency in mechanical reasoning also explain the distinctive symptoms of ideo-motor apraxia?

Consider first the inability to imitate meaningless gestures ( $§ 6.1)$. A promising hypothesis is that it involves a failure in body part coding (cf. [Goldenberg, 1996], [Goldenberg, 2013, pp. 110-114], [Goldenberg and Strauss, 2002], [Goldenberg and Spatt, 2009]). Body part coding is a cognitive process whereby the representation of a gesture is reduced to the representation of simple spatial relationships between body parts ([Brass and Heyes, 2005], [De Vignemont et al., 2006], [De Vignemont et al., 2009]). As [Goldenberg, 2013, p. 128] has noted, mechanical reasoning and body part coding resemble each other so much that it makes sense to deem them as species 
of the same broad cognitive capacity. They differ on the sort of inputs that characterize them visual representation of gestures in the case of imitation, verbal representation of the task in the case of mechanical reasoning. They also differ in that mechanical reasoning typically involves tools, whereas body part coding is used more generally - not just in transitive gestures but also in intransitive ones. Both cognitive mechanisms operate by mapping a representation of a gesture or a task into a representation of its corresponding body parts; they both are generative, in that a multitude of mechanical devices can be constructed by a combination of a limited number of functional parts and their properties and a multitude of body movements can be constructed by a combination of a limited number of body parts and properties ([Osiurak, 2009], [Osiurak, 2011]).

So impairment in mechanical reasoning and body part coding might explain impairment in the ability to imitate meaningless gestures. What about the evidence concerning apraxia in pantomiming tasks? In pantomiming tasks, the gesture is not environmentally cued; moreover, it is to be made in rather unusual and novel circumstances - ones that do not involve the tool(s) that that kind of gesture typically involves. So in pantomiming tasks too, patients have to 'deliberate' about how to execute a rather novel task - i.e., they have to map the representation of the verbal command into a novel sequence of body parts and bodily movements. This mapping will also involve segmenting a representation of the task into parts and putting them in correspondence with different types of bodily movements. This sort of deliberation will also have to involve the capacity for the sort of body part coding and mechanical problem-solving that play a crucial role in the imitation tasks and in novel tool tasks.

By contrast, consider the conditions where apractic agents can perform the gesture with no mistakes - when the task is familiar and environmentally cued. In these cases, it is very plausible that agents do not need to plan how to perform the action in the same ways that they have to do it in unfamiliar tasks or in pantomiming tasks. When the task is familiar, the environmental cue triggers a response by triggering the corresponding motor routine (or action schema, or control policy) for the task, and so the agent does not need to reason productively about how to perform the action. In this sense, the action is triggered bottom-up, rather than top-down. So, in these conditions, the agent does not have to engage in the sort of mechanical reasoning that is required for non-environmentally triggered tasks. 


\subsection{Mechanical reasoning as productive reasoning}

The similarities between these cognitive mechanisms suggest a more general incapacity for productive reasoning. Indeed, mechanical reasoning and body part coding are candidates for being species of productive reasoning, for they doubly dissociate from declarative knowledge and they are available to central cognition rather than modular.

The first observation is that the capacity for mechanical reasoning and declarative knowledge about a task can doubly dissociate. The first direction of dissociation is that one can have a loss of declarative knowledge with preserved mechanical reasoning. Patients with semantic dementia lose declarative knowledge of objects and tools so they cannot recall the names of the tools or cannot explain the typical functions of the tools. They even show severe impairment on tests of functional associations, where the task consists of matching tools with the functions associated with them by social conventions ([Sirigu et al., 1991], [Buxbaum et al., 1997], [Lauro-Grotto et al., 1997], [Hodges et al., 2000], [Osiurak et al., 2008], [Hodges et al., 1999], [Negri et al., 2007], [Negri et al., 2007], [Silveri and Ciccarelli, 2009]). The second direction of dissociation is of the sort illustrated by ideo-motor apraxia. As we have seen, apractic patients score above average in tests on associating tools with their functions and their typical tasks but who score below average in mechanical reasoning ([Goldenberg and Spatt, 2009], [Goldenberg, 2013, p.133]). Similar results had been reached by [Sirigu et al., 1995]. These studies report a woman who could associate instruments to the appropriate function of their application - e.g., she could move the spoon between the table and her mouth and could also move the nail clipper toward her other hand, showing intact declarative knowledge and that she could perform quite well on environmentally triggered tasks, and, therefore, had no problem at the motor-executional level. However, selectively for certain skills such as cutting meat or brushing her teeth, she would show serious difficulties in adapting the position of her hand to the functional requirement of the relevant tool. For example, rather than holding the spoon between her thumb, her index and her middle finger, with her palm turned slightly upwards to secure maintenance of its horizontal orientation, she would take the spoon with her whole hand and leave the determination of its orientation to chance.

The second important observation is that mechanical reasoning and body part coding are not generally supposed to be the sole working of discrete subpersonal systems (such as the motor sys- 
tem). For neither mechanical reasoning nor body part coding are informationally insulated. As [Goldenberg, 2013, p. 13] notices, mechanical reasoning presupposes knowledge about general principles of physics and mechanics — knowledge acquired by lifelong experience with moving and acting in a three-dimensional world. The same holds for body part copying: it requires a lot of knowledge about the features and boundaries of the body parts that pertain to human bodies regardless of individual variations in size or shape and regardless of changes in body configuration brought about by movements of the limbs or the whole body ([Brass and Heyes, 2005], [De Vignemont et al., 2009], [De Vignemont et al., 2006]). Both processes engage working memory and depend on representations stored in working memory ([Sims and Hegarty, 1997, p. 330], [Wilson, 2001], [Hegarty, 2004]). Thus, mechanical reasoning seems available to central cognition and if so, it is a candidate for being a species of productive reasoning in the sense introduced in $\S 3$.

\section{Discussion}

On the explanation of ideo-motor apraxia just proposed, ideo-motor apractic patients are deficient in a distinctively productive kind of reasoning. This sort of reasoning is necessary to find innovative solutions to novel problems. It is also important when the subjects are asked to reproduce unfamiliar sequences of movements in unusual circumstances (as in the manikin experiments, or in pantomiming tasks) as well as when a familiar task is to be initiated by the subject in absence of environmental triggers. By contrast, environmentally triggered tasks that apractic patients can perform are not deliberative activities (though they might be intentional): they are automatic — they are triggered by environmental cues rather than by a subject's deliberation (they are bottom-up, rather than top-down). So, they do not need productive reasoning. This diagnosis of ideo-motor apraxia is clearly present in [Goldenberg, 2013] who proposes we understand ideo-motor apraxia as a '... a disturbance of mental control of deliberate motor actions'.

This concludes the argument from ideo-motor apraxia to the psychological reality of productive reasoning. But, as we noted at the outset ( $(3)$, evidence for a personal-level, distinctively productive kind of reasoning that doubly dissociates from declarative knowledge as well as from observational knowledge is also evidence for concepts with the functional profile of practical concepts. Hence, this also concludes the argument for the psychological reality of practical concepts. 
Let me end by considering some important objections.

Is the current explanation of ideo-motor apraxia predicated on the assumption that apractic patients do not use practical concepts in familiar and environmentally triggered tasks? For example, when an apractic patient waves goodbye to a person they see leaving, do not they have to conceptualize the occasion as needing a response in order for them to be able to wave successfully? If so, do not they need to possess practical concepts already?

Notice that there is no straightforward argument from their ability to automatically perform complex tasks in familiar circumstances to their possessing practical concepts. As we have seen, apractic agents retain their semantic as well as their observational concepts, and those already might explain their ability to automatically perform familiar tasks. Perception of affordances ([Osiurak et al., 2017]) might also explain their recognizing the situation as in need of action when the triggers are present.

That said, the current explanation of ideo-motor apraxia is not incompatible with apractic subjects' retaining practical concepts for familiar tasks all along. It might be that they have the concepts but just that they cannot use them in productive reasoning. Indeed, recall that apractic patients can perform on demand simple motor tasks, like raising their arm and reaching for a bottle in their visual field. Their ability to plan simple tasks such as these suggests that they might possess practical concepts for those simple tasks. The important point for my argument is that apractic patients are impaired in productive reasoning — in their ability to plan complex tasks. This impairment manifests in their inability to form new practical concepts of novel and unfamiliar complex tasks as well as in their inability to deploy practical concepts in planning those same tasks on demand. This impairment is evidence that productive reasoning is psychologically real in normal subjects and so, given the functional characterization in $\S 3$, it is evidence that there are concepts with the functional profile of practical concepts. While I cannot rule out that apractic patients retain practical concepts for familiar complex tasks all along (and simply cannot use them in productive reasoning), for my argument to go through, I do not need to rule that out.

A salient alternative hypothesis that I have not considered so far is that apractic patients have impaired abilities to imagine actions or, in some cases, objects (or objects that are conceptualized in terms of actions), to imaginatively decompose objects into their constituent parts, and to imagine complex actions and decompose those imagined actions into their constituent parts properly 
sequenced. Indeed, cognitive scientists have found that mechanical reasoning is frequently accompanied by imagery and that it involves mental simulation ([Hegarty, 2004]). Moreover, some findings do suggest that often apraxia deficits can go together with an inability to answer imagery questions about joint movement or the spatial position of the hands during action with their eyes closed/ when they do not have visual access to their limb placement ([Ochipa et al., 1997]).

However, the sort of mental simulation that is central to productive reasoning is not simply manipulation of imagery. Rather, it also includes representations of non-visible properties and can be used in conjunction with non-imagery processes, such as task decomposition and rule-based reasoning ([Hegarty, 2004, pp. 282-283]). So, while both imaginistic representation and mental simulation are definitely important to mechanical reasoning, it is doubtful that a deficit in mechanical reasoning can be explained entirely in terms of a deficit in imaginistic representations. Indeed, the findings concerning apractic patients' inability to answer imagery questions is taken by cognitive scientists to suggest at most that the same representations used for gesture production are also activated during imagery of motor acts (e.g, [Ochipa et al., 1997]). Finally, note that it is not incompatible with how we have been thinking of practical concepts that they might involve (without being exhausted by) imaginistic representations. For recall that I have not been assuming much about the format of such representations, except that they are combinatorial and compositional, that they figure in productive intentions and represent a task in terms of its executable parts. ${ }^{24}$ Indeed, as noted at the outset $\S 3$, under some typing there might be more than one kind of representation that satisfies the functional role of practical concepts. ${ }^{25}$

\footnotetext{
${ }^{24} \mathrm{~A}$ referee objects that it is not obvious that imaginistic representations of actions should be considered practical concepts since they are not obviously necessary for intentional responses to typical environmental cues and the referee thinks that practical concepts should be involved in such responses. As we have seen, I don't think it is obvious that practical concepts are involved for performing familiar tasks in environmentally triggered conditions (perception of affordances, semantic or observational concepts might explain those performances). Nor is it part of the functional characterization given in $\S 3$ that practical concepts are involved in environmentally triggered responses. Indeed, those responses don't seem to involve productive reasoning.

${ }^{25} \mathrm{~A}$ referee asks whether it could be that apractic patients have more general memory problems, that prevents them from learning any new concepts. However, as discussed in $\S 4$, there is no evidence that it is common to all apractic patients that they have more general memory problems (though some have Alzheimer's, not all do cf [Wheaton and Hallett, 2007, p. 1]). A referee further asks whether apractic subjects may be missing the ability to perform tasks on demand, because they cannot or call up the action schemas on the basis of novel activators. Note that
} 
One final objection is worth considering: have I cherry-picked evidence? Ideo-motor apraxia is a multi-faceted deficit and there are several issues regarding diagnosing it — for example, many apractic patients possess different deficits, such as Wernicke's aphasia, agnosia, asymbolia, and Alzheimer's. Even the boundaries between ideo-motor apraxia and other forms of apraxia such as conceptual or ideational apraxia - are at times quite blurred. Partly because of this, there is no consensus about how to characterize ideo-motor apraxia. For example, some think that some apractic patients also lose the ability to spontaneously perform motor tasks (cf. e.g., [Wheaton and Hallett, 2007], while others take it to be definitional of ideo-motor apraxia that the ability to perform motor task depends on the circumstances of the testing ([De Renzi et al., 1980], [De Renzi, 1989], [De Renzi, 1999], [Goldenberg, 2008], [Goldenberg, 2013]). There is also some reason to think that it may not be a single disorder or that its symptoms might not have a single cause ([Goldenberg, 2013]). ${ }^{26}$

In response, while I submit that the characterization of ideo-motor apraxia that I have worked with is currently widely endorsed among the most prominent researchers on the deficit (e.g, [Leiguarda et al., 1994 [Krakauer and Shadmehr, 2007][Osiurak, 2011], [Goldenberg, 2008], [Goldenberg, 2013], [Osiurak, 2011]), ultimately my argument doesn't depend on whether or not 'ideo-motor apraxia' picks out a unique neuro-psychological deficit. The evidence marshaled above concerning the Novel Tool Test and the Meaningless Gestures Test suggests that there is such a thing as productive reasoning, which is involved in planning how to perform tasks and is particularly important in cases of tasks that are novel. This productive reasoning demonstrably dissociates from declarative knowledge (and so from semantic concepts) as well as from observational concepts. Modulo the functional characterization of practical concepts provided in $\S 3$, this is evidence for the psychological reality of practical concepts, whether or not 'ideo-motor apraxia' picks out a unique neuro-psychological deficit.

this explanation assumes — like the popular explanation — they have already action schemas for tasks they have not encountered before, and we have seen from the Novel Tool Test that that is not true.

${ }^{26} \mathrm{I}$ am grateful to an anonymous reviewer for raising this objection in this form. 


\section{Comparisons}

Let me compare the argument developed in this paper to other recent discussions of ideo-motor apraxia. [Pacherie, 2011] has argued that apractic subjects lack concepts with the functional profile of practical concepts — which she calls 'executable concepts':

People suffering from ideo-motor apraxia know what one is supposed to do to perform a certain action, they know, say, that waving goodbye involves moving one's arm and hand in a certain way and they can recognize that someone is waving goodbye when seeing them. What they can't do is consciously and voluntarily initiate and perform the action in the absence of environmental triggers ([Wheaton and Hallett, 2007]). In other words, they have intact motor representations of the relevant movements, they have concepts of the types of movements associated with an action enabling them to describe or recognize them, but what they seem to have lost are executable concepts of the types of movements ... Lacking those executable concepts, they are unable to voluntarily initiate motor actions.

From Pacherie's conclusion that ideo-motor apraxia is a deficit in practical concepts, one might then conclude that in normal subjects, practical concepts are psychologically real. This line of argument for the psychological reality of practical concepts would, however, be far too quick: as we have seen, more argument is needed to rule out the popular explanation. On the popular explanation, ideo-motor apraxia is not necessarily a deliberative deficit (as already noted in $\S 8$ ) nor does it have to be a conceptual deficit: the ability to retrieve control policies on demand does not have to be explained in terms of concept possession - a brute ability does the work. The argument developed in this paper from ideo-motor apraxia to the psychological reality of practical concepts significantly differs from Pacherie's. An important difference between my argument and that suggested by Pacherie's quote is that, whereas Pacherie concludes that apractic patients "lack" executable concepts altogether, as I noted in $\S 8$ my argument is not incompatible with apractic subjects actually retaining practical concepts for familiar tasks and for simple tasks, and simply not being able to use them in productive reasoning (and so not being able to produce novel practical concepts). Indeed, I do believe that apractic patients' preserved ability to perform simple motor tasks on demand is evidence that, at least for those simple tasks, they possess the corresponding 
practical concepts. If so, Pacherie's diagnosis of ideo-motor apraxia is incorrect. My proposal is, instead, that what is missing in apractic subjects is the ability to plan complex tasks from simpler ones - i.e., the capacity for productive reasoning.

Finally, let me compare my argument with [Mylopoulos and Pacherie, 2017]'s interface argument for practical concepts. My argument differs from this interface argument in that it does not share its presuppositions. Whereas the interface argument presupposes that there are subpersonal motor representations, this assumption is not needed for my argument. On my explanation of ideo-motor apraxia, this is a deficit in productive reasoning, which is the ability to plan complex motor tasks. Productively reasoning involves decomposing the task in terms of simpler and simpler movements. A representation of the resulting decomposition specifies a way to perform the task - a productive intention - which represents the task to be performed through a practical concept. This story leaves open that the motor system might then execute a productive intention that is output of productive reasoning without issuing intermediate subpersonal motor representations of the motor goals between practical concepts of a task and its execution. My argument also leaves open that, if there are subpersonal motor representations, they might have a format akin to conceptual representations, as empiricists think ([Barsalou et al., 1999], [Prinz, 2004]). So, the argument stands whether or not there is an genuine interface problem, in [Butterfill and Sinigaglia, 2014]'s sense, to be addressed. Finally, my argument does not rely on practical concepts being able to solve interface problem. Indeed, I share the concerns that others have expressed with a solution to the interface argument which appeals to intermediate representations between intentions and motor representations rather than to meta-representational rules for translating representations in one code into representations into another code (cf. [Christensen, 2020]). Because the argument developed here does not depend on the same presuppositions, it attains a generality that the interface argument lacks.

\section{Conclusions}

Practical concepts have been invoked in epistemology, philosophy of mind, and philosophy of psychology and yet evidence for positing practical concepts has not been closely scrutinized. The argument developed here relies on evidence for the role of productive reasoning in skilled delib- 
erate behavior - the Novel Tool Task and the Meaningless Gestures Task - evidence which has not been previously discussed in the philosophical debate about skilled action nor has been brought to bear in the context of an argument for practical concepts.

I have not tried to argue that practical concepts are always needed for skilled behavior. As we have seen, productive reasoning plays a crucial role in skilled deliberative behavior but might be dispensed with when the task is familiar and environmentally triggered. Even so, the story I have put forward does suggest that skillfully performing a task on demand requires productive reasoning. Moreover, productive reasoning is needed to form novel practical concepts - an ability which is in turn needed for flexibly adjusting to novel circumstances. Thus, to the extent to which the marks of skillfulness are the capacity for control and the capacity to flexibly adjust to novel circumstances, the argument does seem to suggest that apractic agents are less than fully skilled at the task. So, although the argument presented here does not go as far as establishing that productive reasoning is always required for skilled performance, it does suggest that, in a fuller sense, skilled actions require practical concepts.

\section{References}

[Anscombe, 1963] Anscombe, G. E. M. (1963). Intention. Blackwell, Oxford.

[Baddeley, 1992] Baddeley, A. (1992). Working memory. Science, 255(5044):556-559.

[Baddeley, 1996] Baddeley, A. (1996). The concept of working memory. Models of short-term memory, pages 1-27.

[Barsalou et al., 1999] Barsalou, L. W. et al. (1999). Perceptual symbol systems. Behavioral and brain sciences, 22(4):577-660.

[Bartolo et al., 2001] Bartolo, A., Cubelli, R., Della Sala, S., Drei, S., and Marchetti, C. (2001). Double dissociation between meaningful and meaningless gesture reproduction in apraxia. Cortex, 37(5):696-699.

[Boghossian, 2003] Boghossian, P. (2003). Blind reasoning. Aristotelian Society Supplementary Volume, 77(1). 
[Brass and Heyes, 2005] Brass, M. and Heyes, C. (2005). Imitation: is cognitive neuroscience solving the correspondence problem? Trends in cognitive sciences, 9(10):489-495.

[Bratman et al., 1987] Bratman, M. et al. (1987). Intention, plans, and practical reason, volume 10. Harvard University Press Cambridge, MA.

[Broome, 2002] Broome, J. (2002). Practical reasoning. Reason and nature: Essays in the theory of rationality, pages $85-111$.

[Butterfill and Sinigaglia, 2014] Butterfill, S. A. and Sinigaglia, C. (2014). Intention and motor representation in purposive action. Philosophy and Phenomenological Research, 88(1):119145.

[Buxbaum et al., 1997] Buxbaum, L. J., Schwartz, M. F., and Carew, T. G. (1997). The role of semantic memory in object use. Cognitive Neuropsychology, 14(2):219-254.

[Buxbaum et al., 2003] Buxbaum, L. J., Sirigu, A., Schwartz, M. F., and Klatzky, R. (2003). Cognitive representations of hand posture in ideomotor apraxia. Neuropsychologia, 41(8):10911113.

[Camp, 2009] Camp, E. (2009). Putting thoughts to work: Concepts, systematicity, and stimulusindependence. Philosophy and Phenomenological Research, 78(2):275-311.

[Campbell, 1996] Campbell, J. (1996). Shape properties, experience of shape and shape concepts. Philosophical Issues, 7:351-363.

[Carey, 2009] Carey, S. (2009). Oxford series in cognitive development: Vol. 3. the origin of concepts. new york, ny, us: Oxford university press.

[Chalmers, 2004] Chalmers, D. J. (2004). 13 phenomenal concepts and the knowledge argument. There's Something About Mary: Essays on phenomenal consciousness and Frank Jackson's knowledge argument, page 269.

[Christensen, 2020] Christensen, W. (2020). The skill of translating thought into action: framing the problem. Review of Philosophy and Psychology, pages 1-27. 
[De Renzi, 1989] De Renzi, E. (1989). Apraxia. In F., B. and J., G., editors, Handbook of clinical neuropsychology. Elsevier, Amsterdam.

[De Renzi, 1999] De Renzi, E. (1999). Apraxia. In Handbook of clinical neuropsychology, Vol. 2 , pages 421-440. Psychology Press.

[De Renzi, 2012] De Renzi, E. (2012). Action. In Ramsey, K. F. . W., editor, The Cambridge handbook of cognitive science, pages 92-111. Cambridge Universitu Press, Cambridge.

[De Renzi et al., 1980] De Renzi, E., Motti, F., and Nichelli, P. (1980). Imitating gestures: a quantitative approach to ideomotor apraxia. Archives of neurology, 37(1):6-10.

[De Vignemont et al., 2009] De Vignemont, F., Majid, A., Jola, C., and Haggard, P. (2009). Segmenting the body into parts: evidence from biases in tactile perception. Quarterly Journal of Experimental Psychology, 62(3):500-512.

[De Vignemont et al., 2006] De Vignemont, F., Tsakiris, M., and Haggard, P. (2006). Body mereology. Human body perception from the inside out, pages 147-170.

[D'Esposito and Postle, 2015] D’Esposito, M. and Postle, B. R. (2015). The cognitive neuroscience of working memory. Annual review of psychology, 66.

[Drayson, 2014] Drayson, Z. (2014). The personal/subpersonal distinction. Philosophy Compass, 9(5):338-346.

[Dummett, 1993] Dummett, M. (1993). The seas of language. Oxford University Press, Oxford.

[Ezcurdia, 1998] Ezcurdia, M. (1998). The concept-conception distinction. Philosophical Issues, 9:187-192.

[Ferrari et al., 2005] Ferrari, P. F., Rozzi, S., and Fogassi, L. (2005). Mirror neurons responding to observation of actions made with tools in monkey ventral premotor cortex. Journal of cognitive neuroscience, 17(2):212-226.

[Fodor, 998a] Fodor, J. (1998a). Concepts: Where Cognitive Science Went Wrong. Clarendon Press, Oxford. 
[Fridland, 2019] Fridland, E. (2019). Intention at the interface. Review of Philosophy and Psychology, pages 1-25.

[Gallese and Lakoff, 2005] Gallese, V. and Lakoff, G. (2005). The brain's concepts: The role of the sensory-motor system in conceptual knowledge. Cognitive neuropsychology, 22(3-4):455479.

[Geschwind and Damasio, 1985] Geschwind, N. and Damasio, A. R. (1985). Apraxia. Handbook of clinical neurology, 1(49):423-432.

[Gibbs, 2005] Gibbs, R. W. (2005). The psychological status of image schemas. From perception to meaning: Image schemas in cognitive linguistics, 29:113-136.

[Gibbs Jr, 2003] Gibbs Jr, R. W. (2003). Embodied experience and linguistic meaning. Brain and language, 84(1):1-15.

[Glick, 2011] Glick, E. (2011). Abilities and Know How Attributions. In Brown, J. and Gerken, M., editors, Knowledge Ascriptions, pages 120-139. Oxford University Press, Oxford.

[Goldenberg, 1995] Goldenberg, G. (1995). Imitating gestures and manipulating a mannikin—the representation of the human body in ideomotor apraxia. Neuropsychologia, 33(1):63-72.

[Goldenberg, 1996] Goldenberg, G. (1996). Defective imitation of gestures in patients with damage in the left or right hemispheres. Journal of Neurology, Neurosurgery \& Psychiatry, 61(2):176-180.

[Goldenberg, 1999] Goldenberg, G. (1999). Matching and imitation of hand and finger posturesin patients with damage in the left or right hemispheres. Neuropsychologia, 37(5):559-566.

[Goldenberg, 2001] Goldenberg, G. (2001). Imitation and matching of hand and finger postures. Neuroimage, 14(1):S132-S136.

[Goldenberg, 2008] Goldenberg, G. (2008). Apraxia. Handbook of clinical neurology, 88:323338.

[Goldenberg, 2013] Goldenberg, G. (2013). Apraxia: The cognitive side of motor control. Oxford. 
[Goldenberg and Hagmann, 1997] Goldenberg, G. and Hagmann, S. (1997). The meaning of meaningless gestures: A study of visuo-imitative apraxia. Neuropsychologia, 35(3):333-341.

[Goldenberg and Hagmann, 1998] Goldenberg, G. and Hagmann, S. (1998). Tool use and mechanical problem solving in apraxia. Neuropsychologia, 36(7):581-589.

[Goldenberg et al., 2007] Goldenberg, G., Hartmann-Schmid, K., Sürer, F., Daumüller, M., and Hermsdölrfer, J. (2007). The impact of dysexecutive syndrome on use of tools and technical devices. Cortex, 43(3):424-435.

[Goldenberg and Spatt, 2009] Goldenberg, G. and Spatt, J. (2009). The neural basis of tool use. Brain, 132(6):1645-1655.

[Goldenberg and Strauss, 2002] Goldenberg, G. and Strauss, S. (2002). Hemisphere asymmetries for imitation of novel gestures. Neurology, 59(6):893-897.

[Goldenberg et al., 1986] Goldenberg, G., Wimmer, E., Auff, G., and Schnaberth (1986). Impairment of motor planning in patients with parkinson's disease: evidence from ideomotor apraxia. Journal of Neurology, Neurosurgery, and Psychiatry, 49:1266-1272.

[Hampe and Grady, 2005] Hampe, B. and Grady, J. E. (2005). From perception to meaning: Image schemas in cognitive linguistics, volume 29. Walter de Gruyter.

[Harman, 1976] Harman, G. (1976). Practical reasoning. The Review of Metaphysics, pages 431463.

[Harman, 2008] Harman, G. (2008). Change in View: Principles of Reasoning. Cambridge University Press.

[Hartmann et al., 2005] Hartmann, K., Goldenberg, G., Daumüller, M., and Hermsdörfer, J. (2005). It takes the whole brain to make a cup of coffee: the neuropsychology of naturalistic actions involving technical devices. Neuropsychologia, 43(4):625-637.

[Hayakawa et al., 2015] Hayakawa, Y., Fujii, T., Yamadori, A., Meguro, K., and Suzuki, K. (2015). A case with apraxia of tool use: selective inability to form a hand posture for a tool. Brain and nerve = Shinkei kenkyu no shinpo, 67(3):311-316. 
[Hegarty, 2004] Hegarty, M. (2004). Mechanical reasoning by mental simulation. Trends in cognitive sciences, 8(6):280-285.

[Heilman and L., 1993] Heilman, K. and L., R. (1993). Apraxia. In KM Heilman, E. V., editor, Clinical Neuropsychology, page 141-164. Oxford University Press.

[Heilman et al., 1997] Heilman, K. M., Maher, L. M., Greenwald, M. L., and Rothi, L. J. (1997). Conceptual apraxia from lateralized lesions. Neurology, 49(2):457-464.

[Higginbotham, 1998] Higginbotham, J. (1998). Conceptual competence. Philosophical Issues, 9:149-162.

[Hodges et al., 2000] Hodges, J. R., Bozeat, S., Ralph, M. A. L., Patterson, K., and Spatt, J. (2000). The role of conceptual knowledge in object use evidence from semantic dementia. Brain, 123(9):1913-1925.

[Hodges et al., 1999] Hodges, J. R., Spatt, J., and Patterson, K. (1999). "what" and "how": evidence for the dissociation of object knowledge and mechanical problem-solving skills in the human brain. Proceedings of the National Academy of Sciences, 96(16):9444-9448.

[Hutto, 2005] Hutto, D. D. (2005). Knowing what? radical versus conservative enactivism. Phenomenology and the Cognitive Sciences, 4(4):389-405.

[Hutto and Myin, 2012] Hutto, D. D. and Myin, E. (2012). Radicalizing enactivism: Basic minds without content. Mit Press.

[Israel et al., 1993] Israel, D., Perry, J., and Tutiya, S. (1993). Executions, motivations, and accomplishments. The Philosophical Review, 102(4):515-540.

[Jarry et al., 2013] Jarry, C., Osiurak, F., Delafuys, D., Chauviré, V., Etcharry-Bouyx, F., and Le Gall, D. (2013). Apraxia of tool use: more evidence for the technical reasoning hypothesis. Cortex, 49(9):2322-2333.

[Jeannerod, 2006] Jeannerod, M. (2006). Motor cognition: What actions tell the self. 42. Oxford University Press. 
[Johnson, 2012] Johnson, M. (2012). Action, embodied meaning, and thought. In Action, Perception and the Brain, pages 92-116. Springer.

[Kenny, 2010] Kenny, A. (2010). Concepts, brains, and behaviour. Grazer Philosophische Studien, 81(1):105-113.

[Kertesz and Hooper, 1982] Kertesz, A. and Hooper, P. (1982). Praxis and language: the extent and variety of apraxia in aphasia. Neuropsychologia, 20(3):275-286.

[Krakauer, 2019] Krakauer, J. W. (2019). The intelligent reflex. Philosophical Psychology, 32(5):822-830.

[Krakauer, 2020] Krakauer, J. W. (2020). Automatizing knowledge: Confusion over what cognitive neuroscience tells us about intellectualism. In The Routledge Handbook of Philosophy of Skill and Expertise, pages 219-225. Routledge.

[Krakauer and Shadmehr, 2007] Krakauer, J. W. and Shadmehr, R. (2007). Towards a computational neuropsychology of action. Progress in brain research, 165:383-394.

[Lande, 2018] Lande, K. J. (2018). The perspectival character of perception. The Journal of Philosophy, 115(4):187-214.

[Lande, 2020] Lande, K. J. (2020). Mental structures. Noûs.

[Laurence and Margolis, 1999] Laurence, S. and Margolis, E. (1999). Concepts: where cognitive science went wrong. jerr a fodor. The British Journal for the Philosophy of Science, 50(3):487491.

[Lauro-Grotto et al., 1997] Lauro-Grotto, R., Piccini, C., and Shallice, T. (1997). Modalityspecific operations in semantic dementia. Cortex, 33(4):593-622.

[Lehmkuhl et al., 1983] Lehmkuhl, G., Poeck, K., and Willmes, K. (1983). Ideomotor apraxia and aphasia: An examination of types and manifestations of apraxic symptoms. Neuropsychologia, 21(3):199-212. 
[Leiguarda et al., 1994] Leiguarda, R., Lees, A., Merello, M., Starkstein, S., and Marsden, C. (1994). The nature of apraxia in corticobasal degeneration. Journal of Neurology, Neurosurgery \& Psychiatry, 57(4):455-459.

[Liepmann, 1900] Liepmann, H. (1900). Das krankheitsbild der apraxie (motorische asymbolie): Auf grund eines falles von einseitiger apraxie. Monatschrift für Psychiatrie und Neurologie, 8:15-44.

[Liepmann, 1906] Liepmann, H. (1906). Der weitere krankheitsverlauf bei dem einseitig apraktischen und der gehirnbefund auf grund von serienschnitten. European Neurology, 19(3):217-243.

[Macauley and Handley, 2005] Macauley, B. L. and Handley, C. L. (2005). Gestures produced by patients with aphasia and ideomotor apraxia. Contemporary Issues in Communication Science and Disorders, 32(Spring):30-37.

[Machery, 2009] Machery, E. (2009). Doing without concepts. Oxford University Press.

[Merleau-Ponty, 1962] Merleau-Ponty, M. (1962). Phenomenology of perception. London, New York: Routledge.

[Mosdell, 2019] Mosdell, M. (2019). Modeling practical thinking. Mind \& Language, 34(4):445464.

[Murphy, 2004] Murphy, G. (2004). The big book of concepts. MIT press.

[Mylopoulos and Pacherie, 2017] Mylopoulos, M. and Pacherie, E. (2017). Intentions and motor representations: The interface challenge. Review of Philosophy and Psychology, 8(2):317-336.

[Negri et al., 2007] Negri, G. A., Lunardelli, A., Reverberi, C., Gigli, G. L., and Rumiati, R. I. (2007). Degraded semantic knowledge and accurate object use. Cortex, 43(3):376-388.

[Noë, 2005] Noë, A. (2005). Anti-Intellectualism. Analysis, 65(288):278-90.

[Ochipa et al., 1997] Ochipa, C., Rapcsak, S. Z., Maher, L. M., Rothi, L. J. G., Bowers, D., and Heilman, K. M. (1997). Selective deficit of praxis imagery in ideomotor apraxia. Neurology, 49(2):474-480. 
[Osiurak et al., 2008] Osiurak, F., Aubin, G., Allain, P., Jarry, C., Richard, I., and Le Gall, D. (2008). Object usage and object utilization. a single-case study. Neurocase, 14(2):169-183.

[Osiurak and Badets, 2016] Osiurak, F. and Badets, A. (2016). Tool use and affordance: Manipulation-based versus reasoning-based approaches. Psychological review, 123(5):534.

[Osiurak et al., 2013] Osiurak, F., Jarry, C., Lesourd, M., Baumard, J., and Le Gall, D. (2013). Mechanical problem-solving strategies in left-brain damaged patients and apraxia of tool use. Neuropsychologia, 51(10):1964-1972.

[Osiurak et al., 2017] Osiurak, F., Rossetti, Y., and Badets, A. (2017). What is an affordance? 40 years later. Neuroscience \& Biobehavioral Reviews, 77:403-417.

[Osiurak, 2011] Osiurak, F. a. a. (2011). Re-examining the gesture engram hypothesis. new perspectives on apraxia of tool use. Neuropsychologia, 49(3):299-312.

[Osiurak, 2009] Osiurak, F. e. a. (2009). Unusual use of objects after unilateral brain damage. the technical reasoning model. Cortex, 45(6):769-783.

[Pacherie, 2000] Pacherie, E. (2000). The content of intentions. Mind \& Language, 15(4):400432.

[Pacherie, 2011] Pacherie, E. (2011). Nonconceptual representations for action and the limits of intentional control. Social Psychology, 42(1):67.

[Pavese, 2013] Pavese, C. (2013). The Unity and Scope of Knowledge. PhD thesis, Rutgers University.

[Pavese, 2015a] Pavese, C. (2015a). Knowing a rule. Philosophical Issues, 25(1):165-188.

[Pavese, 2015b] Pavese, C. (2015b). Practical senses. Philosopher's Imprint, 15(29).

[Pavese, 2017a] Pavese, C. (2017a). Know-how and gradability. The Philosophical Review, 126(3):345-383.

[Pavese, 2017b] Pavese, C. (2017b). A theory of practical meaning. Philosophical Topics, 45(2):65-96. 
[Pavese, 2019] Pavese, C. (2019). The psychological reality of practical representation. Philosophical Psychology, 32(5):784-821.

[Pavese, 2020] Pavese, C. (2020). Practical representation. In Routledge Handbook of Philosophy of Skills and Expertise, pages 226-44. Routledge.

[Pavese, 2021] Pavese, C. (2021). Might there actually be practical concepts? manuscript.

[Pavese, ming] Pavese, C. (forthcoming). Knowledge-how. Stanford Encyclopedia of Philosophy.

[Peacocke, 1988] Peacocke, C. (1988). Thoughts: An Essay on Content. Number vol. 4 in Aristotelian Society Series. Blackwell.

[Peacocke, 1992] Peacocke, C. (1992). A study of concepts. The MIT Press.

[Peigneux et al., 2000] Peigneux, P., Van der Linden, M., Andres-Benito, P., Sadzot, B., Franck, G., and Salmon, E. (2000). Exploration neuropsychologique et par imagerie fonctionnelle cérébrale d'une apraxie visuo-imitative. Revue Neurologique, 156(5):459-474.

[Pinker, 2007] Pinker, S. (2007). The stuff of thought: Language as a window into human nature. Penguin.

[Poeck, 1986] Poeck, K. (1986). The clinical examination for motor apraxia. Neuropsychologia, 24(1):129-134.

[Prinz, 2004] Prinz, J. J. (2004). Furnishing the mind: Concepts and their perceptual basis. MIT press.

[Quilty-Dunn, 2021] Quilty-Dunn, J. (2021). Polysemy and thought: Toward a generative theory of concepts. Mind \& Language.

[Quilty-Dunn and Mandelbaum, 2018] Quilty-Dunn, J. and Mandelbaum, E. (2018). Inferential transitions. Australasian Journal of Philosophy, 96(3):532-547.

[Quine, 1960] Quine, W. (1960). Word and Object. Cambridge, Massachussetts. MIT Press., Cambridge. 
[Rapcsak et al., 1995] Rapcsak, S. Z., Ochipa, C., Anderson, K. C., and Poizner, H. (1995). Progressive ideomotor apraxia-evidence for a selective impairment of the action production system. Brain and cognition, 27(2):213-236.

[Rizzolatti et al., 2002] Rizzolatti, G., Fogassi, L., and Gallese, V. (2002). Motor and cognitive functions of the ventral premotor cortex. Current opinion in neurobiology, 12(2):149-154.

[Rizzolatti and Sinigaglia, 2008] Rizzolatti, G. and Sinigaglia, C. (2008). Mirrors in the brain: How our minds share actions and emotions. Oxford University Press, USA.

[Sathian et al., 2011] Sathian, K., Buxbaum, L. J., Cohen, L. G., Krakauer, J. W., Lang, C. E., Corbetta, M., and Fitzpatrick, S. M. (2011). Neurological principles and rehabilitation of action disorders: common clinical deficits. Neurorehabilitation and neural repair, 25(5_suppl):21S$32 \mathrm{~S}$.

[Schiffer, 2002] Schiffer, S. (2002). Amazing Knowledge. Journal of Philosophy, 99(4):200-202.

[Searle et al., 1983] Searle, J. R., Willis, S., et al. (1983). Intentionality: An essay in the philosophy of mind. Cambridge university press.

[Sekinea and Rosec, 2013] Sekinea, K. and Rosec, M. L. (2013). The relationship of aphasia type and gesture production in people with aphasia. American Journal of Speech-Language Pathology, 662:672.

[Silveri and Ciccarelli, 2009] Silveri, M. C. and Ciccarelli, N. (2009). Semantic memory in object use. Neuropsychologia, 47(12):2634-2641.

[Sims and Hegarty, 1997] Sims, V. K. and Hegarty, M. (1997). Mental animation in the visuospatial sketchpad: Evidence from dual-task studies. Memory \& Cognition, 25(3):321-332.

[Sirigu et al., 1995] Sirigu, A., Cohen, L., Duhamel, J.-R., Pillon, B., Dubois, B., and Agid, Y. (1995). A selective impairment of hand posture for object utilization in apraxia. Cortex, 31(1):41-55.

[Sirigu et al., 1991] Sirigu, A., Duhamel, J.-R., and Poncet, M. (1991). The role of sensorimotor experience in object recognition: A case of multimodal agnosia. Brain, 114(6):2555-2573. 
[Spatt et al., 2002] Spatt, J., Bak, T., Bozeat, S., Patterson, K., and Hodges, J. R. (2002). Apraxia, mechanical problem solving and semantic knowledge. Journal of Neurology, 249(5):601-608.

[Stanley, 2011] Stanley, J. (2011). Know How. Oxford University Press, Oxford.

[Stanley and Williamson, 2001] Stanley, J. and Williamson, T. (2001). Knowing How. Journal of Philosophy, 98(8):411-444.

[Strawson, 2010] Strawson, G. (2010). Mental Reality (Representation and Mind). MIT Press.

[Weiskopf, 2015] Weiskopf, D. (2015). Observational concepts. The Conceptual Mind: New Directions in the Study of Concepts, pages 223-247.

[Weiskopf, 2020] Weiskopf, D. A. (2020). Anthropic concepts. Nô̂s, 54(2):451-468.

[Wermter et al., 2005] Wermter, S., Palm, G., and Elshaw, M. (2005). Biomimetic neural learning for intelligent robots: Intelligent systems, cognitive robotics, and neuroscience, volume 3575. Springer.

[Wheaton and Hallett, 2007] Wheaton, L. A. and Hallett, M. (2007). Ideomotor apraxia: a review. Journal of the neurological sciences, 260(1-2):1-10.

[Wilson, 2001] Wilson, M. (2001). The case for sensorimotor coding in working memory. Psychonomic bulletin \& review, 8(1):44-57.

[Zalta, 2001] Zalta, E. (2001). Fregean senses, modes of presentation, and concepts. Philosophical Perspectives, 15:335-359. 